\title{
Open design: non-professional user-designers creating products for citizen science, a case study of beekeepers.
}

\author{
Robert Phillips, Yelena Ford, Karl Sadler, Sarah Silve and Sharon Baurley
}

Brunel University, Kingston Lane, Uxbridge, Middlesex, UB8 3PH

info@rdphillips.co.uk

Keywords: User centred design, user-designers, open design, open fabrication, citizen science, beekeeping

\begin{abstract}
Affiliated technologies have opened up opportunities for people, no matter what their design competency or expertise, to engage in the design of the products they use. The notion of "Open Design" or the open sharing of information relating to the design and manufacture of products, services or objects, can be seen as part of a much more encompassing phenomenon whereby users are the innovators and fabricators of their own products. Digital fabrication can enable the remote fabrication of objects tailoring artefacts to specific users or environmental needs. Open fabrication makes manufacturing processes accessible and can respond to niche needs with bespoke production. Citizen science uses non-professionals to conduct research in their own environment or location, extending the impact of research. This process of "amateur scientist" and community monitoring has positive and negative aspects that design can help to address.
\end{abstract}

The workshop conducted as part of this research involved 15 amateur beekeepers and led to a probe study involving 150 participants in the UK, testing a new approach to co-collaboration yielding positive outcomes. The bee population is currently under threat from environmental change, pollution, disease and they are users with a specific interest, bespoke needs and a knowledge base outside of their profession. The decline in bees is a scientific issue as they are seen as a barometer for the health of the environment. Through analysis of observations and insights gained through active design-led workshops, this paper examines the potential barriers, opportunities, benefits and pitfalls of user-designers engaging with citizen science using open design and open fabrication tools. Workshop results included: methods, motivations, designer and manufacturer opportunities and insights into repeatable processes forming the start of a citizen science toolkit. The objective was to ascertain the possible pitfalls of a group of user-designers creating their own citizen science tools enabled by technologists and designers.

adfa, p. 1, 2011.

(c) Springer-Verlag Berlin Heidelberg 2011 


\section{Introduction}

Open design is the "free distribution, documentation and permission of modifications and derivations" of an object, product or service (Van Abel, 2011). This approach "empowers people to make and understand products and processes, with more transparency" leading to more independent user-led design (Van Abel 2011). Open design is optimised by personal fabrication creating physical "things" from digital data (Gershenfeld 2005). Personal fabrication enables products to be widely distributed, as plans can be downloaded and products assembled with the correct tools and knowledge in place.

The Internet has evolved the accessibility of information. "[The Internet] Weblogs and Wikis have been readily adopted in civil society and are transforming the way many of us access information," spreading information and data for either re-appropriation or use (Hasan, Pfaff 2006). These processes, "personal fabrication" and "accessible information," are enabling userdesigners to create their own solutions. Personal fabrication can cater to "product niches" (low volume products) emerging from user or designer insights, due to the lowering of entry costs (Von Hippel 2005).

"Users as designers are a combination of existing and customized participatory and empathic design methods that help to facilitate the dialogue needed to illicit personal and contextual information that helps define the user's needs and wants" (Resink, van Dijk \& Reitenbach 2011). With the advent of technology, "design is becoming an everyday activity rather than a professional study" (Lee 2007). "Increasingly, the greatest limitation [for personal fabrication] is neither cost nor research; it's simply the awareness of what's already possible," highlighting the need for methodologies and processes to optimise user-designers' possible concepts (Gershenfeld 2005).

Real design participation is do-it-yourself where the participants invent the rules, utilising the users' motivation to steer the design process. The term "citizen science refers to volunteers who participate as field assistants in scientific studies" (Cohn 2008). Open design can facilitate citizen science so participants are not just assistants but active investigators. Participatory design encompasses several methods, with the unifying philosophy that they all 
involve active consultation with users, clients and other stakeholders in the process, ideally through face-to-face contact in activity-based co-design. Methods can include cultural probes, diary studies, photo studies, and collage. Participatory design optimises the use of participants within the creative design process (Hanington, Martin 2012). Examples of open design and citizen science projects include:

- DIY Drones, Ministry of Defence: Technology open sourced for aerial monitoring or mapping of large areas, formed in a web presence with constructional information (Anderson 2012).

- Open PCR (Polymerase chain reaction): A piece of laboratory equipment used in the biotechnology industry to identify bacteria and viruses, matches criminals' DNA to crime scenes and other applications (Anonymous 2012a).

- The Public Laboratory's open balloon monitoring kit: An analogue product with camera attachments to take aerial photographs (Anonymous 2012b).

In these projects the public can make equipment using kits, or from off the shelf and custom components; different skills are required for each project. Some of the project outputs are "socially orientated objectives" as opposed to purely market-led initiatives (Thorpe, Gamman 2011).

Beekeeping has become more complicated in recent years due to viruses and complications, in particular "Colony Collapse Disorder" (CCD), which is alleged to be causing "the vanishing of the bees" (Langworthy G 2009). Commercial beekeepers have reported [bee hive] losses of up to $90 \%$ due to CCD since 2006 (Benjamin, McCallum 2009). With their vital pollinating activities, bees are one of the most ecologically useful and important insects (Cramp 2011). Previous work by the author highlighted the motivations of beekeepers are not just related to honey production, but also their concern about environmental issues and personal interest (Phillips Robert, S Silve and S Baurley 2013).

\section{$2 \quad$ Method}

Designers need "information about the contexts of people's interactions with products in order to design products that fit into the lives of the people who will use them" (Visser et al. 2005). This work focused on gathering insights from 
active experienced and novice beekeepers, highlighting opportunities and pitfalls for a partnership between citizen science and open design. The project brought together industry partners, the British Bee Keeping Association (BBKA) and the Honey Club, a social innovation initiative run by the Wolff Olins brand agency. The BBKA was used to recruit participants, to ensure a spread of participants' location and experience. The endorsement of an independent respected group (the BBKA) validated our approach from our participants' perspective. The workshops were not initially "looking for commercial pay-offs," as this can narrow potential outcomes (Wilkie et al. 2010). For effective participant engagement the following steps were used:

- Familiarity with subject area and focus to achieve concise outcomes.

- Concepts communicated in analogies or via storytelling.

- Prioritising user insights and needs with technology focus a close second.

- Group review in case other parties see value in redundant concepts.

- No requirement of prior knowledge in technology or design.

- The possibility for participants to openly interpret workshop material, encouraging new insight.

- Designers/facilitators accurately translating from users' insight to concept.

- User narration of concept functions, guiding parties in their process of use.

On arrival participants were issued with a sketchbook used as a graphical questionnaire. The session started with a briefing on open design and citizen science. The briefing covered: project examples, design intentions and objectives of the session. Attendees were assigned one of three types of role: facilitator, designer, or beekeeper (main participants) all centred on "common goals" around the discipline of beekeeping (Ozkaya, Akin 2005). The participatory processes involved the use of large printed posters on which was posed a set of questions. Participants worked in teams of 5 to generate answers in a discursive manner (Figs. 1, 2). Tasks were broken down into discrete sections, narrowing the design direction and focusing participants' thinking with each step, using guidelines from action research and participatory design (Robson 2002). 


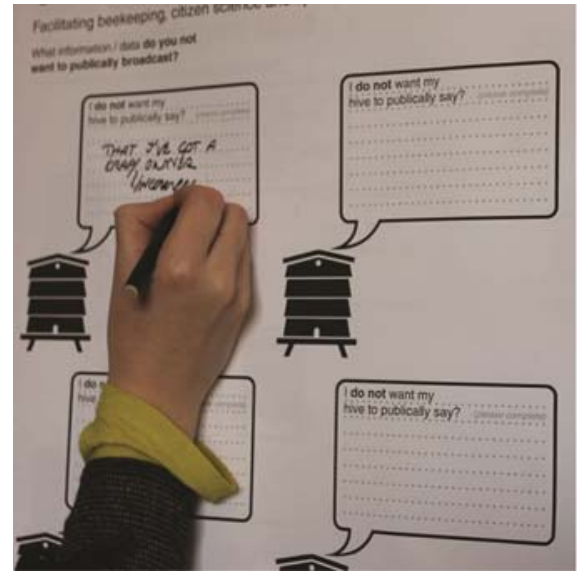

Fig. 1. Workshop large prints

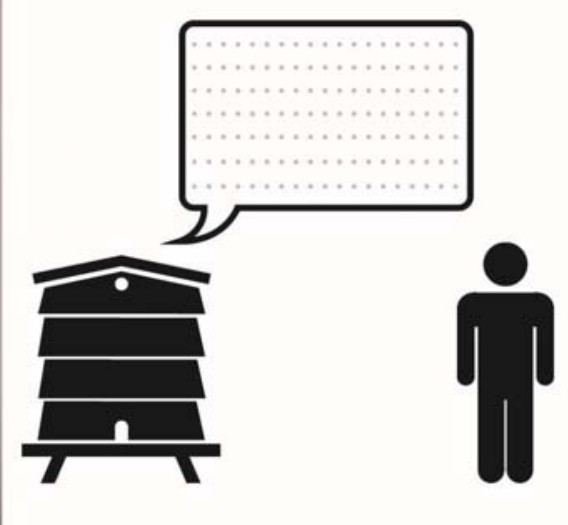

Fig. 2. Workshop graphic

Objects printed on the posters were given quotation spaces to help the participants' imagination in talking to; bee hives, bees, bee environments and beekeeping equipment like a concept cartoon (Figs. $3 \& 4$ ). The quotation space gave objects a human quality, removing technological fears and "humanising the technology" (Hardwick 2000). The questions were placed on the large prints and acted as a basis and a framework for reflection by the participants.

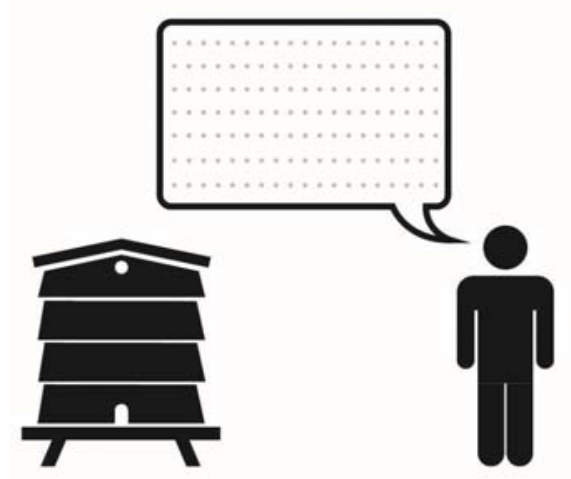

Fig. 3. Workshop graphic

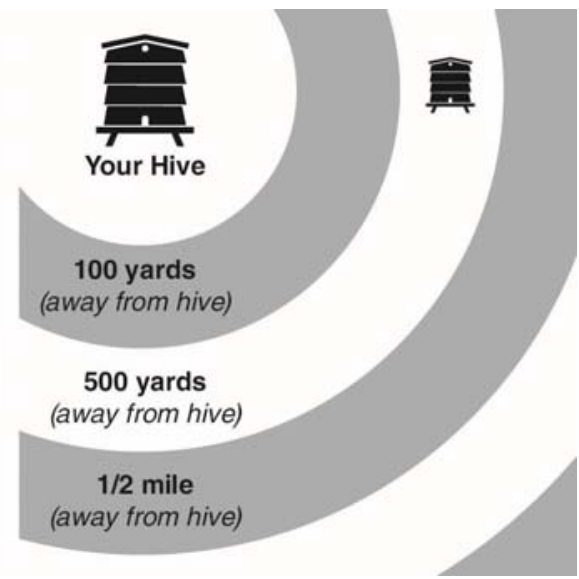

Fig. 4. Graphic for location data

The questions include: 
1. If your hive/hives could talk, what information would you like it to tell you?

2. Inside the hive, map/draw what you would like to know?

3. Outside the hive, map/draw what you would like to know from the surrounding environment?

4. Map/draw what you would like to know from your neighbours hive/hives?

5. What information/data do you not want to publically broadcast?

A discussion finalised opportunities for beekeeping citizen devices, during which each team presented back to the whole group.

\section{$3 \quad$ Insights and key outcomes}

The workshop highlighted the need for several beekeeping monitoring devices for disease, honey yield, pollution monitoring and the travelling distance of foraging bees. Whilst these insights are interesting, they also brought about opportunities for wider applications with design and manufacturing stakeholders. Insights also drew attention to future work with potential barriers and pitfalls that could affect concept device creation for citizen science using open design. The most surprising insight was how the participants had to be guided and almost advised not to design but narrate their day to day activities to the designers and facilitators. Further questions for citizen science and open design raised by the workshop include:

- How users opt out of data gathering if they feared it could be detrimental?

- Who is responsible for the data created?

- Are there possible negative legacies of data collected?

- Which project stakeholder should lead the collaboration?

- How will these ventures raise initial capital?

- How do we design products to avoid false positives?

- How does the science community feel about enhancing the public's capability to widen research participation and community monitoring?

- Should a design system be closed at certain project points?

- How do you ensure accurate scientific deployment of device in the field?

- Transparency with users whilst maintaining ethical and data protection standards. 
- Opportunities explored with a suitable experienced team.

\section{Discussion}

Creating multi-disciplinary teams in the workshop ensured that the "Two key elements [to project success], community and technology" were present, as "in isolation neither functions" (Hess 1979). The workshop used posters for the participants to annotate their feedback and ideas, "equipping them with creative ways to express themselves" (LUMA Institute 2012). The open-ended graphics on the posters meant participants could openly interpret material leading to more fruitful insights and ideas (Björgvinsson 2008). The posters also provoked discussions with participants who often had product or equipment ideas but lacked the knowledge to develop concepts into physical objects. Group review and open discussion was important to the workshop as it allowed both positive and redundant concepts to be identified. The participants' motivations were: fuelling their interest in beekeeping, concern for their local community, concern for the environment and respect for the workshop host (Wolff Olins/Honey Club).

The participants knew that an independent research team of entomologists would review the concepts gauging their value for further scientific research. This validation meant the workshop participants could be disposable with their concepts as they were going to be reviewed by professional experts. The resulting insights and methodologies could lead to the creation of a citizen science toolkit, widening the potential reach of the research. The toolkit and process need to consider positives and negatives of the citizen science and open design partnership. Repeatability of the workshop with different scientific disciplines would highlight more positive and negative insights and possibly areas of scalability. Collaborators, users, scientists or designers could use toolkits to mutually benefit all stakeholders through sales, data gathered and by furthering research in unfunded areas. Design lessons can be learnt from these users as they are using stock products for unique opportunities. The user's products could trickle down to wider audiences, possibly leading to international inquiry relying on third party instructions. 


\subsection{Designers' opportunities (from workshop insights)}

The design of systems or objects consists of specific parameters that constrain outputs. These constraints can be in the form of design processes and new methodologies to help create new concepts. The following insights could be opportunities for the design of systems for open design and citizen science:

- A safety standards system for users to understand their application.

- Manufacturing process, material or mechanical optimisation systems through accessible testing software.

- Guidance for users on monitoring applications, not just technology.

- Product design for deconstruction, enabling user repair or disassembly for use in other artefacts.

- Systems that allow third party quality control and trouble shooting.

- Concept translation tools, ensuring clarity from user insight to desired product.

- Design toolkits to explore open design and citizen science applications.

\subsection{Manufacturers' opportunities (from workshop insights)}

Manufacturers can use open design as an opportunity to create assemblies responding to user-designers' needs in self-assembly kit form. Stock digital parts/components can be created for use in construction kits, increasing accessibility for a user-designer. User-designers can then adapt and reappropriate kits for their own needs, creating their own product. Selfassembly kits are not new; users have assembled furniture, cars and clothes for generations. Kits help users customise at the source of creation in line with personal needs, catering to activities that were previously difficult due to the cost of manufacture. The following insights could be opportunities for manufacturers within the field of open design and citizen science:

- A library of open mechanisms/sub-assemblies for specific applications compliant with industry standards, for use in controlled conditions.

- Creating open fabrication analysis tools enhancing manufactured outputs. 
- Using open design as a process for distributing goods/products over a wider area with less environmental impact and more localised production.

\section{Conclusion and further work}

The objective of the study was to ascertain the possible pitfalls of users creating "citizen monitoring" equipment advancing a wider approach to scientific research and the initiation of a citizen science/open design toolkit. Userdesigners require access to design and communication tools that meet their skill competency and requirements. Open design can streamline relevant commercial processes, removing stumbling blocks for user-designers. Based on the workshop outcome and insights, the following further work is proposed:

- Address the needs of a wider group of scientists or scientific issue.

- Review the streamlining of manufacturing processes for effective user participation according to their skill levels or knowledge base.

- Review other areas of research and investigate how the partnership of citizen science and open design can further them or will not function.

- Collaborate with government, charities or relevant NGO's.

\section{References}

Anderson, C. 2012, DIY DRONES. Available: http://diydrones.com/ [2012, November, 12].

Anonymous 2012a, Open PCR. Available: http://openpcr.org/ [2012, November, 12].

Anonymous 2012b, The Public Laboratory for open technology and science. Available: http://publiclaboratory.org/home [2012, November, 12].

Björgvinsson, E.B. 2008, "Open-ended participatory design as prototypical practice", CoDesign, vol. 4, no. 2, pp. 85-99.

Carson, K.A. 2009, "The Homebrew Industrial Revolution", Center for a Stateless Society Paper No.

Cohn, J.P. 2008, "Citizen science: Can volunteers do real research?", Bioscience, vol. 58, no. 3, pp. 192-197.

Cramp, D. 2011, The Complete Step-By-step Book of Beekeeping, 1st edn, Lorenz Books, Leicestershire. 
Gershenfeld, N.A. 2005, Fab: the coming revolution on your desktop-from personal computers to personal fabrication, 1st edn, Basic Books, New York.

Hanington, B. \& Martin, B. 2012, Universal Methods of Design: 100 Ways to Research Complex Problems, Develop Innovative Ideas, and Design Effective Solutions, Rockport Pub.

Hardwick, S.W. 2000, "Humanising the technology landscape through a collaborative pedagogy", Journal of Geography in Higher Education, vol. 24, no. 1, pp. 123-129.

Hasan, H. \& Pfaff, C. 2006, "Emergent Conversational Technologies that are Democratising Information Systems in Organisations: the case of the corporate Wiki", Information Systems Foundations, pp. 197.

Hess, K. 1979, Community technology, Harper and Row, New York; London.

Keogh, B. 1999, "Concept cartoons, teaching and learning in science: an evaluation", International Journal of Science Education, vol. 21, no. 4, pp. 431-446.

Langworthy G, H.M. 2009, The Vanishing of the Bees, 1st edn, Hive Mentality Films, USA.

Lee, D.R.Y. 2007, "Designing for the people, with the people and by the people ".

LUMA Institute 2012, Innovating for people, handbook of human centred design methods, First edition edn, LUMA Institute, Pittsburgh.

Ozkaya, I. \& Akin, Ö. 2005, "Use of requirement traceability in collaborative design environments", CoDesign, vol. 1, no. 3, pp. 155-167.

Phillips Robert, S Silve and S Baurley 2013, (in press) "The practical maker: investigating the definitions and requirements of and exploring the motivations behind bespoke making.", (Accepted for publication 2013).

Resink, E., Van Dijk, D. \& Reitenbach, M. 2011, "waag society".

Robson, C. 2002, Real world research: a resource for social scientists and practitionerresearchers, Blackwell Oxford.

Thorpe, A. \& Gamman, L. 2011, "Design with society: why socially responsive design is good enough", CoDesign, vol. 7, no. 3-4, pp. 217-230.

Van Abel, B. 2011, Open design now: why design cannot remain exclusive, Bis, Amsterdam.

Visser, F.S., Stappers, P.J., Van der Lugt, R. \& Sanders, E.B.N. 2005, "Context mapping: experiences from practice", CoDesign, vol. 1, no. 2, pp. 119-149.

Von Hippel, E. 2005, Democratizing innovation, the MIT Press.

Wilkie, A., Gaver, W., Hemment, D. \& Giannachi, G. 2010, "Creative assemblages: organisation and outputs of practice-led research", Leonardo, vol. 43, no. 1, pp. 98-99. 